\title{
Capillary pressure estimates from arterial and venous occlusion in intact dog lung
}

\author{
M. Corboz, S. Sanou, F.A. Grimbert
}

Capillary pressure estimates from arterial and venous occlusion in intact dog lung. M. Corboz, S. Sanou, F.A. Grimbert. @ERS Journals Ltd 1995.

ABSTRACT: We performed pulmonary venous occlusions in order to check the validity of the pulmonary capillary pressure measurements obtained using pulmonary arterial occlusion in the intact animal.

The venous and arterial postocclusion pressure profiles were recorded using balloon catheters introduced, respectively, into a left lower lobe vein and into a right pulmonary artery in the anaesthetized open-chest dog.

The pressure profiles were fitted by a biexponential function with an early exponential and a late exponential presenting, respectively, a short and a long time constant. We used the zero-time extrapolation of the late slow exponential to obtain an arterial $(\boldsymbol{P} \mathrm{c}, \mathrm{ao})$ and a venous $(\boldsymbol{P} \mathrm{c}, \mathrm{vo})$ estimate of the pulmonary capillary pressure. Each $\boldsymbol{P}_{\mathrm{c} \text {,ao }}$ and $\boldsymbol{P}$ c,vo made it possible to calculate a fractional arterial or venous pressure gradient when referenced to the arteriovenous pressure gradient measured during the occlusion process. In nine dogs, when referenced to the whole lung, the arterial, middle and venous fractional pressure gradients were $37 \pm 11,10 \pm 6$, and $53 \pm 12 \%$, respectively.

As the middle fractional pressure gradient is low, we conclude that pulmonary capillary pressure estimates from arterial occlusion are close to the venous occlusion estimates of capillary pressure in the intact dog lung.

Eur Respir J., 1995, 8, 1122-1129.
Laboratoire de Physiologie Respiratoire Expérimentale, Théorique et Appliquée, and Département de Physiologie, Faculté de Médecine de Grenoble, Université Joseph Fourier, La Tronche, France.

Correspondence: F.A. Grimbert Laboratoire P.R.E.T.A.

Département de Physiologie

Faculté de Médecine de Grenoble 38700 La Tronche

France

Keywords: Capillary pressure, intact dog lung, pulmonary arterial and venous occlusion pressure, pulmonary pressure gradient distribution

Received: September 61994

Accepted after revision March 141995

This work was supported by grants from the Université Joseph Fourier (Grenoble I).
The pulmonary capillary pressure $\left(P_{\mathrm{c}}\right)$ is the major determinant of the net filtration pressure across the pulmonary microcirculation. $P_{\mathrm{c}}$ has been estimated in open-chest animals [1-3], and in patients [4, 5], using the analysis of the pressure-time profiles following the occlusion of a lobar or of a sublobar pulmonary artery by means of a balloon-tipped catheter. The arterial postocclusion pressure-time profiles initially exhibit a rapidly decaying segment, followed by a slowly decaying "exponential-like" segment. The techniques of analysis of these profiles are based on a model of the pulmonary circulation where most of the vascular compliance is located in the pulmonary capillaries and where most of the vascular resistance lies in the small pulmonary arteries and veins. According to this model, following the occlusion of the pulmonary artery, the pressure falls rapidly to the level of the capillary pressure and then decays more slowly as the capillary blood volume is drained through the veins. Two techniques of analysis are widely used to estimate $P_{\mathrm{c}}$ from the arterial postocclusion pressuretime profiles. The first technique equates $P_{\mathrm{c}}$ to the zerotime extrapolation of the exponential fit of the slowly decaying segment $[2,6]$. The second technique equates $P_{\mathrm{c}}$ to the inflection point between the rapidly and slowly decaying segments $[2,3,7,8]$.

The $P_{\mathrm{c}}$ estimate from the arterial postocclusion profiles $(P \mathrm{c}$, ao $)$ has been compared to other estimates of $P_{\mathrm{c}}$ from venous postocclusion profiles $\left(P_{\mathrm{c}, \mathrm{vo})}\right)$, or from simultaneous arterial and venous occlusion, namely double occlusion $\left(P_{\mathrm{c}, \mathrm{do})}\right)$. These different estimates give different values of $P_{\mathrm{c}}$ in isolated lung preparations [7,9-11]. $P_{\mathrm{c}, \mathrm{ao}}$ is above $P_{\mathrm{c}, \mathrm{do}}$, which is itself above $P_{\mathrm{c}, \mathrm{vo}} . P_{\mathrm{c}}$,ao and $P_{\mathrm{c}, \mathrm{vo}}$ make it possible to partition longitudinally the arteriovenous pressure difference in an arterial fraction $(\triangle \mathrm{Pa})$ between the pulmonary arterial pressure $(P \mathrm{a})$ and $P_{\mathrm{c}, \mathrm{ao}}$, a middle fraction $(\Delta \mathrm{Pm})$ between $P_{\mathrm{c}, \mathrm{ao}}$ and $P_{\mathrm{c}, \mathrm{vo}}$, and a venous fraction $(\Delta \mathrm{Pv})$ between $P$ c,vo and the pulmonary venous pressure $(P \mathrm{v})$.

Such knowledge is important in order to correctly interpret a modification of $P_{\mathrm{c}, \mathrm{ao}}$, the only estimation of $P_{\mathrm{c}}$ available in patients. $P_{\mathrm{c}}$,ao will not be a good estimate of $P_{\mathrm{c}}$ in man if the middle fraction of the $P \mathrm{a}-P_{\mathrm{v}}$ difference is as large as observed in isolated dog lung preparations [7, 9-11]. In the intact dog lung, $P$ c,vo was previously compared to $P_{\mathrm{c}, \text { ao }}$ in only one study, the study of HollowAY et al. [3]. In the later study, $P_{\mathrm{c}}$,ao was below $P_{\mathrm{c}, \mathrm{vo}}$, so that no middle pressure gradient was observed; in fact, it was negative [3]. As the data of this study in intact lung conflicted with those obtained in isolated lung preparations, we compared $P_{\mathrm{c} \text {,ao }}$ to $P_{\mathrm{c}, \mathrm{vo}}$ estimates of $P_{\mathrm{c}}$ in the anaesthetized dog in order to reassess the importance of the middle pressure gradient in the intact lung.

A left thoracotomy was performed, as in the study by Holloway et al. [3], because this preparation has the additional advantage of making it possible to estimate lung transvascular filtration by the canulation of a prenodal 
lymphatic vessel [12]. In addition, the present study was used to compare the characteristics of the venous occlusion profiles to those of the well-known arterial profiles. The influence of pharmacological vasoconstriction and vasodilatation of the pulmonary circulation on $P_{\mathrm{c}, \mathrm{ao}}, P_{\mathrm{c}, \mathrm{vo}}$ and on the $P \mathrm{c}$, ao- $P$ c,vo gradient was also tested.

\section{Material and methods}

\section{Experimental preparation}

Mongrel dogs of both sexes $(12-16 \mathrm{~kg})$ were placed in the supine position, anaesthetized with sodium thiopental (30-40 mg. $\mathrm{kg}^{-1} i . v$.) and mechanically ventilated. Inspiratory $\mathrm{O}_{2}$ fraction was maintained at 0.30 by supplementing the inspired air with oxygen. The end-expiratory pressure was set at $2-3 \mathrm{cmH}_{2} \mathrm{O}$ when the chest was open. The oesophageal temperature was monitored and maintained at $37^{\circ} \mathrm{C}$. A catheter was placed into the carotid artery for sampling arterial blood and monitoring systemic arterial pressure. A catheter was introduced via a jugular vein into the right atrium for administering fluids and drugs. Heparin was given $\left(50 \mathrm{iu} \cdot \mathrm{kg}^{-1}\right)$ in order to avoid the occurrence of clots at the catheter tips.

The dog was placed laterally to perform a left thoracotomy through the 7 th or 8 th intercostal space. Pressure transducers were zeroed at the level of the left atrium. A catheter was introduced into the left atrial appendage to measure the left atrial pressure $\left(P_{\mathrm{LA}}\right)$. In all experiments $(n=9)$, a $7 \mathrm{~F}$ Swan-Ganz thermodilution catheter was floated via a jugular vein into the pulmonary artery to perform an arterial occlusion in the right (dependent i.e the lower lung in the lateral position) lung. The venous occlusion was performed in the non-dependent i.e. the upper lung in the lateral position (left) lung in six experiments. A $6 \mathrm{~F}$ Berman angiographic balloon catheter presenting multiple perforations proximal to the balloon was inserted downstream into the pulmonary vein draining the left lower lobe. Owing to the short length of the pulmonary vein available to surgery, only the perforations most proximal to the balloon could be left in the vessel in order to allow the measurement of the venous occlusion pressure profiles. The other perforations were sealed. We assumed that $P_{\mathrm{c}, \text { vo }}$ was measured in zone 3 condition even in the nondependent lung, as $P$ c,vo is estimated from the final part of the venous occlusion curve, hence at high pressure. In order to validate this assumption, the $P \mathrm{c}$,vo and the fractional venous pressure gradient $(\Delta P \mathrm{v})$ were compared to those of an additional group $(n=3)$, where the venous catheter was positioned in the dependent (right) lung. In this group, a $6 \mathrm{~F} \mathrm{Swan-}$ Ganz catheter was advanced upstream into the pulmonary vein draining the right lower lobe.

Following surgery, additional heparin was infused (25 iu $\left.\cdot \mathrm{kg}^{-1} \cdot \mathrm{h}^{-1}\right)$ and respiratory muscle paralysis was maintained with pancuronium bromide $\left(0.1 \mathrm{mg} \cdot \mathrm{kg}^{-1}\right)$. The $\mathrm{pH}$ was adjusted to normal value, whenever necessary, by the addition of sodium bicarbonate, and the ventilatory rate was adjusted throughout the experiment to maintain normal blood gases.

\section{Acquisition and interpretation of the occlusion curves}

The electrical signals from the pressure transducers were amplified by Hewlett-Packard 78342A bedside monitors, digitized at $100 \mathrm{~Hz}$ on a microcomputer and stored for subsequent analysis. During the acquisition of each occlusion pressure-time profile, the ventilator was turned off for approximately $10 \mathrm{~s}$, whilst keeping the end-expiratory pressure constant. Each acquisition included $3 \mathrm{~s}$ of the pressure trace before occlusion and the post-occlusion profile until the pressure reached a constant level. The period of venous occlusion was kept as short as possible, in order to prevent the development of pulmonary oedema upstream of the balloon.

To characterize the biexponential model of the pulmonary arterial postocclusion profile, the following equation was used:

$$
P \mathrm{a}(t)=P \mathrm{v}, \mathrm{ao}+P 1 \mathrm{e}^{-(t-t 0) / t_{1}}+P 2 \mathrm{e}^{-(t-t 0) / t_{2}}
$$

with $P_{1}+P_{2}=P_{\mathrm{a}}(t 0)-P_{\mathrm{v}, \mathrm{ao}} ; P_{\mathrm{v}, \text { ao: }}$ venous pressure after arterial occlusion (obtained from the stable part of the arterial occlusion pressure profile); $t 0$ : instant of occlusion; $t 1$ : time constant of the fast component of the pulmonary arterial occlusion curve; $t 2$ : time constant of the slow component of the pulmonary arterial occlusion curve.

For a venous postocclusion curve, the equation was similar:

$$
P_{\mathrm{V}}(t)=P \text { a,vo }-P 1 \mathrm{e}^{-t(t-t 0) / t 1}-P 2 \mathrm{e}^{-(t-t 0) / t 2}
$$

with $P$ a,vo: arterial pressure after venous occlusion (obtained from the stable part of the venous occlusion pressure profile).

A segment of the arterial postocclusion pressure profile, starting at the instant of occlusion $t 0$ and excluding the stable part of the postocclusion profile, was fitted by the biexponential model. The instant of occlusion $t 0$ was identified by visual inspection as the time at which the arterial pressure waveform completed its deviation from the previous pulses. The data points of the selected segment were fitted by the above biexponential model. The goodness of fit was expressed by the mean square error between the data and the model normalized to $\left(P \mathrm{a}(0)-P_{\mathrm{v}, \mathrm{oa}}\right)^{2}$. The model parameters $(\mathrm{P} 1 / \mathrm{P} 1+\mathrm{P} 2, t 1$ and $t 2)$ were identified.

The pulmonary capillary pressure was determined as the extrapolation to $t 0$ of the second exponential of the biexponential model, whether a pulmonary arterial or venous postocclusion pressure profile was fitted. On the same arterial postocclusion pressure profiles, a comparison was made of the $P$ c,ao estimates obtained by the above method, and those obtained using a method proposed by HAKIM et al. [2], where a segment of the pressure profile, starting $0.3 \mathrm{~s}$ after occlusion and lasting $2 \mathrm{~s}$, is fitted by a single exponential. The $P$ c,ao estimates by the two methods were well correlated $(\mathrm{r}=0.97 ; \mathrm{n}=37 ; \mathrm{p}<0.0001)$.

\section{Experimental protocol}

Several steady-states were obtained during each experiment. The first one was retained as characteristic of 
the control condition. At the beginning and at the end of each steady-state, the cardiac output, the systemic arterial pressure, the pulmonary arterial pressure $P$ a, the pulmonary venous pressure $P_{\mathrm{v}}$, the right atrial pressure, the left atrial pressure $P_{\mathrm{LA}}$ and the intratracheal pressure were measured. During each steady-state, 3-5 arterial occlusions and 3-5 venous occlusions were performed alternately. Each steady-state lasted approximately 15 $\min$.

The effects of the pharmacological substances were tested in the main group $(n=6)$ with the venous catheter in the nondependent lung. Each infusion of pharmacological substances was immediately preceded by a control steady-state. Two substances were tested, first a vasodilator, nitroprusside, second a vasoconstrictor, serotonin.

Sodium nitroprusside (NP) was infused into the right atrium at the rate of approximately $0.015 \mathrm{mg} \cdot \mathrm{kg}^{-1} \cdot \mathrm{min}^{-1}$. The infusion rate was then adjusted to decrease the mean arterial systemic pressure by $20 \%$, until a steady-state was reached and the occlusion data were collected. The nitroprusside infusion was then stopped. The effect of nitroprusside disappeared in 15-20 min, as indicated by the return of the haemodynamic variables to their control values.

Serotonin (5-hydroxytryptamine) was infused at a rate of $0.2 \mathrm{mg} \cdot \mathrm{kg}^{-1} \cdot \mathrm{h}^{-1}$ into the right atrium. The infusion rate was then adjusted to increase the pulmonary arterial pressure by $30 \%$ of the previous control value, until a steady-state was reached and the occlusion data were collected.

\section{Statistical analysis}

The different pressures within the same steady-state in the same group of animals were compared using Student's paired t-test. The haemodynamic variables were compared using analysis of variance (ANOVA) in the two groups of dogs characterized by the position of the venous catheter in the dependent lung or in the nondependent lung. The values of the haemodynamic variables during nitroprusside or serotonin infusion were compared to the control values using Student's paired t-test. All data are presented as mean \pm SD. A p-value of less than 0.05 was considered significant.

\section{Results}

Characteristics of the venous versus arterial postocclusion pressure curves in intact animals

The venous profile presented two sequential components. The initial component was a rapid increase in pressure with a time constant $(t 1)$ of $0.12 \pm 0.06 \mathrm{~s}$. It was followed by a slower exponential increase with a time constant $(t 2)$ of $0.74 \pm 0.37 \mathrm{~s}$, until it stabilized at the level of the pulmonary arterial pressure $P$ a,vo (fig. 1). The arterial occlusion profile was symmetrical to the venous profile. It decreased sharply at first $(t=0.05 \pm 0.02 \mathrm{~s})$, then more slowly $(t 2=1.06 \pm 0.43 \mathrm{~s})$, until it stabilized at the level of the pulmonary arterial occlusion pressure $P_{\mathrm{v}, \text { ao }}$ (fig. 2).

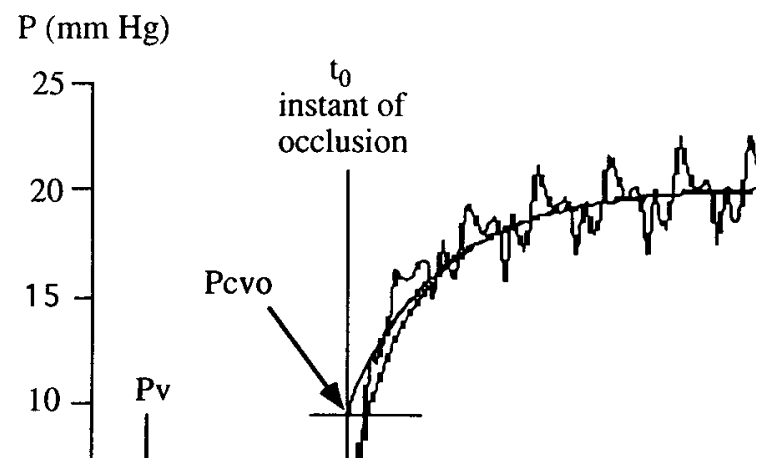

Fig. 1. - Example of a pulmonary venous occlusion curve. The occlusion was performed by the rapid inflation of a balloon catheter in a pulmonary vein. Pulmonary venous pressure $\left(P_{\mathrm{v}}\right)$ increased after the occlusion until it plateaued at the level of the pulmonary arterial pressure $(P$ a,vo). The postocclusion segment was fitted according to a double exponential model. The capillary pulmonary pressure $\left(P_{\mathrm{c}, \mathrm{vo}}\right)$ was estimated by the back-extrapolation of the second exponential to the instant of occlusion ( $t 0)$.

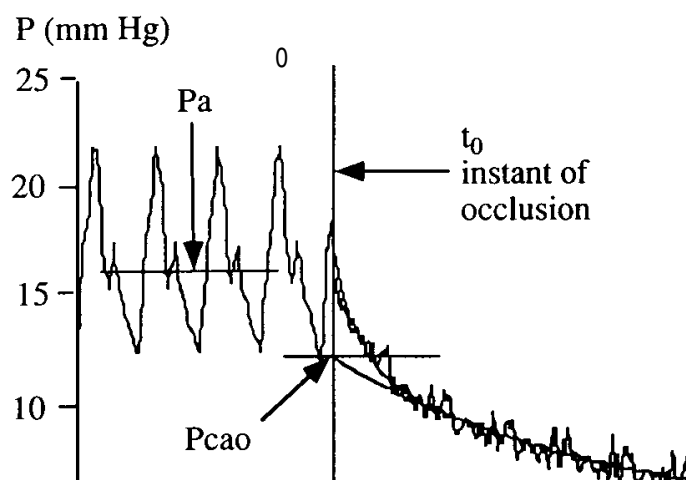

Fig. 2. - Example of a pulmonary arterial occlusion curve. The occlusion was performed by the rapid inflation of a balloon catheter in a pulmonary artery. Pulmonary arterial pressure $(P$ a $)$ decreased after the occlusion until it plateaued at the level of the pulmonary arterial pressure $\left(P_{\mathrm{v}, \mathrm{ao}}\right)$. The postocclusion segment was fitted according to a double exponential model. The capillary pulmonary pressure $\left(P_{\mathrm{c}, \mathrm{ao}}\right)$ was estimated by the back-extrapolation of the second exponential to the instant of occlusion $(t 0)$.

In each control steady-state, the coefficient of variation (CV) $\left(\mathrm{SD} \cdot \mathrm{mean}^{-1}\right)$ of the 3-5 occlusion pressure-time profiles was larger on the venous side than on the arterial side $(\mathrm{CV}=9.45 \pm 4.79$ vs $7.64 \pm 4.14)$.

Longitudinal pulmonary pressure distributions obtained from venous and arterial occlusions (table 1)

Pulmonary arterial and venous pressures. Due to the left thoracotomy, it was more convenient to introduce a balloon-tipped catheter into a pulmonary vein located in the nondependent lung rather than in the dependent lung. We investigated the eventual modifications brought about by the location of the venous catheter in the nondependent lung as compared to its location in the dependent lung. An additional group of experiments $(n=3)$ was, thus, performed with the venous catheter introduced in the dependent lung. The data of all measured variables between the two groups were compared using ANOVA. 
Table 1. - Pulmonary haemodynamic data during the control period

\begin{tabular}{|c|c|c|c|c|c|c|c|c|c|c|c|}
\hline \multirow[t]{2}{*}{ Experiments } & \multicolumn{3}{|c|}{ Arterial occlusion $\mathrm{mmHg}$} & \multicolumn{4}{|c|}{ Venous occlusion $\mathrm{mmHg}$} & \multicolumn{3}{|c|}{ Fractional $\Delta P \quad \%$} & \multirow{2}{*}{$\begin{array}{l}P_{\mathrm{c}} \\
\mathrm{mmHg}\end{array}$} \\
\hline & $P$ a & $P \mathrm{c}$, ao & $P$ v,ao & $P$ a,vo & $P_{\mathrm{c}, \mathrm{vo}}$ & $P_{\mathrm{v}}$ & $P_{\text {LA }}$ & $\Delta P \mathrm{a}$ & $\Delta P_{\mathrm{v}}$ & $\Delta P \mathrm{~m}$ & \\
\hline \multicolumn{12}{|c|}{ Venous occlusion in nondependant lung $(\mathrm{n}=6$ ) } \\
\hline Mean & 17.8 & 12.7 & 4.8 & 17.6 & 11.0 & 4.9 & 3.0 & 40 & 48 & 12 & 11.1 \\
\hline$\pm \mathrm{SD}$ & 2.1 & 2.9 & $1.1^{*}$ & 2.9 & 3.6 & $1.6^{*}$ & 1.2 & 13 & 12 & 7 & 3.1 \\
\hline \multicolumn{12}{|c|}{ Venous occlusion in dependant lung $(n=3)$} \\
\hline Mean & 18.5 & 14.8 & 7.2 & 20.6 & 15.5 & 7.1 & 6.0 & 33 & 62 & 5 & 14.1 \\
\hline$\pm \mathrm{SD}$ & 3.5 & 3.4 & 3.0 & 3.2 & 2.5 & $1.7 *$ & $1.7^{\#}$ & 1 & 2 & 2 & 2.7 \\
\hline \multicolumn{12}{|c|}{ Venous occlusion in nondependant and dependant lungs $(n=9)$} \\
\hline Mean & 18.1 & 13.4 & 5.6 & 18.6 & 12.5 & 5.6 & 4.0 & 37 & 53 & 10 & 12.1 \\
\hline$\pm \mathrm{SD}$ & 2.4 & 3.0 & $2.1^{*}$ & 3.2 & 3.8 & $1.9^{*}$ & 2.0 & 11 & 12 & 6 & 3.2 \\
\hline
\end{tabular}

*: p<0.05 in paired t-tests comparing: 1) $P_{\text {a,vo }}$ to $P_{\mathrm{a}}$; 2) $P_{\mathrm{c}, \text { vo }}$ to $P_{\mathrm{c}, \text { ao }}$ 3) $P_{\mathrm{v}}$ and $P_{\mathrm{v}, \text { ao }}$ to $P_{\mathrm{LA}}$. \#: p $<0.05$ in ANOVA comparing measured and calculated variables in the dependant lung to those in nondependant lung. Haemodynamic data measured by the pulmonary arterial catheter in the dependant lung: $P_{\mathrm{a}}$ : pulmonary arterial pressure; $P_{\mathrm{c}, \text { ao: }}$ pulmonary capillary pressure (estimated

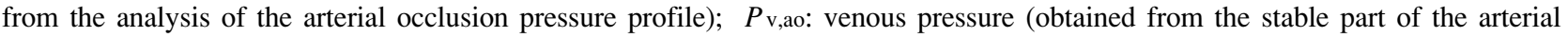
occlusion pressure profile). Haemodynamic data measured by the pulmonary venous catheter in the nondependant lung or in the dependant lung: $P$ a,vo: pulmonary arterial pressure (obtained from the stable part of the venous occlusion pressure profile); $P$ c,vo: pulmonary capillary pressure (estimated from the analysis of the venous occlusion pressure profile); $P$ v: venous pressure; $P$ LA: left atrial pressure. Fractional $\Delta P: \Delta P$ a: fractional arterial pressure gradient $=(P \mathrm{a}-P \mathrm{c}, \mathrm{ao}) /(P \mathrm{a}-P$ v,ao $) ; \Delta P_{\mathrm{v}}$ : fractional venous pressure gradient $=\left(P_{\mathrm{c}, \mathrm{vo}}-P_{\mathrm{v}}\right) /\left(P_{\mathrm{a}, \mathrm{vo}}-P_{\mathrm{v}}\right) ; \Delta P_{\mathrm{m}}$ : fractional middle pressure gradient $=1-\Delta P_{\mathrm{a}}-\Delta P_{\mathrm{v}} ; P_{\mathrm{c}}$ : mean capillary pressure $=P \mathrm{LA}+\left(\left(\Delta P_{\mathrm{v}}+\Delta P \mathrm{~m} / 2\right)(P \mathrm{a}-P \mathrm{LA})\right)$. ANOVA: analysis of variance.

$P_{\text {LA }}$ was significantly higher $(\mathrm{p}<0.05)$ in the group with the venous catheter in the dependent lung $(6.0 \pm 1.1 \mathrm{mmHg})$ than in the group with the venous catheter in the nondependent lung $(3.0 \pm 1.2 \mathrm{mmHg})$. We have no obvious explanation for this $3 \mathrm{mmHg}$ difference, except experimental variability. No other measured pressure was different between the two groups. Therefore, the measured pressure data of the two groups were pooled.

In the pooled data, $P$ a,vo was at the same level as $P$ a $(18.6 \pm 3.2$ vs $18.1 \pm 2.4 \mathrm{mmHg})$, but $P_{\mathrm{v}}$ and $P_{\mathrm{v}, \text { ao }}$ were significantly larger than $P_{\mathrm{LA}}(5.6 \pm 1.9$ and 5.6 $\pm 2.1 \mathrm{vs}$ 4.0 $\pm 2.0 \mathrm{mmHg} ; \mathrm{p}<0.05$ ) (see Discussion).

Longitudinal distribution of $\mathrm{Pc}$ estimates and fractional pressure gradients. There was a trend for $P_{\mathrm{c}, \mathrm{vo}}$ to be lower than $P$ c,ao in the nondependent lung $(11.0 \pm 3.6 \mathrm{vs}$ $12.7 \pm 2.9 \mathrm{mmHg})$ but not in the dependent lung $(15.5 \pm 2.5$ vs $14.8 \pm 3.4 \mathrm{mmHg}$ ) (see Discussion). The mean $P_{\mathrm{c}}$ $(\bar{P})$, calculated as $P_{\mathrm{LA}}+\left(\left(\Delta P_{\mathrm{v}}+\Delta P_{\mathrm{m}} / 2\right)\left(P \mathrm{a}-P_{\mathrm{LA}}\right)\right.$ where $\Delta P \mathrm{~m}$ is the middle pressure gradient), was higher (14.1 \pm 2.7 vs $11.1 \pm 3.1 \mathrm{mmHg}$; NS) in the group with the venous catheter in the dependent lung than in the group with the venous catheter in the nondependent lung. It may reflect the higher level both in venous pressures $\left(P_{\mathrm{v}}, \mathrm{ao}\right.$, $P_{\mathrm{v}}$ and $\left.P_{\mathrm{LA}}\right)$ and $\Delta P_{\mathrm{v}}$ in this group. No estimate of $P_{\mathrm{c}}$ or fractional pressure gradient was significantly different between the two groups. Therefore, the calculated pressure data of the two groups were pooled.

Altogether, in the pooled data, the fractional venous pressure gradient $\Delta P_{\mathrm{v}}$ was larger than the fractional arterial pressure gradient $\Delta P \mathrm{a}(53 \pm 12$ vs $37 \pm 11 \%)$, with a fractional middle pressure gradient $\Delta P \mathrm{~m}$ of $10 \pm 6 \%$. $\overline{P_{\mathrm{c}}}$ was $12.1 \pm 3.2$ $\mathrm{mmHg}$. The cardiac output was $1.7 \pm 0.8 \mathrm{~L} \cdot \mathrm{min}^{-1}$.

\section{Effects of pharmacological stimuli (table 2)} lung.

The pharmacological stimuli were tested in the dependent

Serotonin infusion. The pulmonary arterial pressure increased significantly with serotonin, whether measured with the arterial catheter $(P a)$ or using the occlusion of the venous catheter $(P \mathrm{a}, \mathrm{vo}) . P \mathrm{c}$,ao and $P$ c,vo also increased

Table 2. - Pulmonary haemodynamic data before and during serotonin and nitroprusside infusion

\begin{tabular}{|c|c|c|c|c|c|c|c|c|c|c|c|c|}
\hline \multirow[t]{2}{*}{ Experiments } & \multirow[t]{2}{*}{$\mathrm{n}$} & \multicolumn{3}{|c|}{ Arterial occlusion $\mathrm{mmHg}$} & \multicolumn{4}{|c|}{ Venous occlusion $\mathrm{mmHg}$} & \multicolumn{3}{|c|}{ Fractional $\Delta P \quad \%$} & \multirow{2}{*}{$\begin{array}{c}\bar{P}_{\mathrm{c}} \\
\mathrm{mmHg}\end{array}$} \\
\hline & & $P$ a & $P_{\mathrm{c}, \mathrm{ao}}$ & $P_{\mathrm{V}, \text { ao }}$ & $P$ a,vo & $P_{\mathrm{c}, \mathrm{vo}}$ & $P_{\mathrm{v}}$ & $P_{\mathrm{LA}}$ & $\Delta P$ a & $\Delta P_{\mathrm{v}}$ & $\Delta P \mathrm{~m}$ & \\
\hline Control & 5 & $\begin{array}{l}19.6 \\
(4.6)\end{array}$ & $\begin{array}{l}14.3 \\
(4.2)\end{array}$ & $\begin{array}{l}5.6 \\
(1.3)\end{array}$ & $\begin{array}{l}18.7 \\
(4.9)\end{array}$ & $\begin{array}{l}12.4 \\
(4.2)\end{array}$ & $\begin{array}{c}4.8 \\
(1.8)\end{array}$ & $\begin{array}{c}2.4 \\
(1.5)\end{array}$ & $\begin{array}{l}38 \\
(8)\end{array}$ & $\begin{array}{c}55 \\
(15)\end{array}$ & $\begin{array}{c}6 \\
(16)\end{array}$ & $\begin{array}{l}12.4 \\
(3.8)\end{array}$ \\
\hline $\begin{array}{l}\text { Serotonin } \\
\quad 0.2 \mathrm{mg} \cdot \mathrm{kg}^{-1} \cdot \mathrm{h}\end{array}$ & & $\begin{array}{l}24.1 * \\
(4.0)\end{array}$ & $\begin{array}{l}15.5 \\
(3.8)\end{array}$ & $\begin{array}{c}5.3 \\
(1.5)\end{array}$ & $\begin{array}{l}24.2^{*} \\
(3.9)\end{array}$ & $\begin{array}{l}14.0^{*} \\
(3.5)\end{array}$ & $\begin{array}{c}5.1 \\
(2.0)\end{array}$ & $\begin{array}{l}3.0 \\
(1.2)\end{array}$ & $\begin{array}{l}46^{*} \\
(7)\end{array}$ & $\begin{array}{l}47^{*} \\
(10)\end{array}$ & $\begin{array}{c}7 \\
(14)\end{array}$ & $\begin{array}{l}13.6 \\
(3.0)\end{array}$ \\
\hline Control & 4 & $\begin{array}{l}19.3 \\
(5.4)\end{array}$ & $\begin{array}{l}14.7 \\
(5.3)\end{array}$ & $\begin{array}{c}5.2 \\
(2.0)\end{array}$ & $\begin{array}{l}20.5 \\
(5.3)\end{array}$ & $\begin{array}{l}14.1 \\
(3.1)\end{array}$ & $\begin{array}{c}5.6 \\
(0.9)\end{array}$ & $\begin{array}{c}3.6 \\
(2.1)\end{array}$ & $\begin{array}{c}35 \\
(11)\end{array}$ & $\begin{array}{c}58 \\
(15)\end{array}$ & $\begin{array}{c}8 \\
(23)\end{array}$ & $\begin{array}{l}13.4 \\
(3.6)\end{array}$ \\
\hline $\begin{array}{l}\text { Nitroprusside } \\
\quad 0.015 \mathrm{mg} \cdot \mathrm{kg}^{-1} \cdot \mathrm{h}\end{array}$ & & $\begin{array}{l}13.3^{*} \\
(3.9)\end{array}$ & $\begin{array}{l}10.2^{*} \\
(3.5)\end{array}$ & $\begin{array}{l}3.5^{*} \\
(2.2)\end{array}$ & $\begin{array}{l}14.1^{*} \\
(4.2)\end{array}$ & $\begin{array}{l}8.7 * \\
(3.4)\end{array}$ & $\begin{array}{l}3.6^{*} \\
(1.9)\end{array}$ & $\begin{array}{c}2.9 \\
(2.0)\end{array}$ & $\begin{array}{l}32 \\
(9)\end{array}$ & $\begin{array}{c}48 \\
(18)\end{array}$ & $\begin{array}{l}19 \\
(25)\end{array}$ & $\begin{array}{l}8.9 * \\
(2.8)\end{array}$ \\
\hline
\end{tabular}

Results are mean $( \pm \mathrm{SD}) . *$ : $<0.05$ in paired t-tests between the pharmacological stimuli and their respective control steady states. For abbreviations see legend to table 1 . 
but less than did arterial pressure. No significant changes in venous pressure or in cardiac output were observed.

Following serotonin infusion, the fractional arterial pressure gradient $\Delta P$ a rose from $38 \pm 8$ to $46 \pm 7 \%(\mathrm{p}<0.05)$, while the fractional venous pressure gradient $\Delta P_{\mathrm{v}}$ fell from $55 \pm 15$ to $47 \pm 10 \%(\mathrm{p}<0.05)$. As a result of these opposite changes in $\Delta P$ a and $\Delta P \mathrm{v}$, the fractional middle pressure gradient $\Delta P \mathrm{~m}$ did not change significantly. Also, $\overline{P c}$ did not increase significantly, despite a $4.5 \mathrm{mmHg}$ increment in $P$ a.

Effects of nitroprusside infusion. The pulmonary arterial pressure decreased significantly with nitroprusside, whether measured with $P$ a or with $P$ a,vo. $P$ c,ao and $P$ c,vo decreased significantly (by 4.5 and $5.4 \mathrm{mmHg}$, respectively) almost as much as pulmonary arterial pressure $(6.0 \mathrm{mmHg})$. Venous pressure measurements $\left(P_{\mathrm{v}, \text { ao }}\right.$ and $\left.P_{\mathrm{v}}\right)$ decreased significantly by approximately $2 \mathrm{mmHg}$. No change in cardiac output was observed.

$\Delta P$ a and $\Delta P_{\mathrm{v}}$ decreased following nitroprusside infusion. As a result of these decreases in $\Delta P$ a and $\Delta P_{\mathrm{v}}, \Delta P \mathrm{~m}$ rose $19 \%$, although not significantly (see Discussion). Also, $\bar{P}_{\mathrm{c}}$ fell by $4.5 \mathrm{mmHg}(\mathrm{p}<0.05)$ along with $P_{\mathrm{c}, \text { ao }}$ and $P_{\mathrm{c}, \text { vo. }}$

\section{Discussion}

The arterial occlusion with a Swan-Ganz catheter is ideally suited for the measurement of $P_{\mathrm{c}}\left(P_{\mathrm{c}, \mathrm{ao}}\right)$ in the intact animal, as it can be performed in closed-chest animals. However, the data from isolated lung experiments show that $P_{\mathrm{c}}$,ao overestimates $P_{\mathrm{c}}$ as estimated either from venous occlusion $(P \mathrm{c}, \mathrm{vo})$ or from double occlusion $(P \mathrm{c}, \mathrm{do})$. In isolated lung preparations [7, 9-11], $P_{\mathrm{c}, \text { ao }}$ is usually above $P$ c,do, which is itself above $P$ c,vo. When the zerotime extrapolation of the slow segment technique is used, the $P \mathrm{c}$,ao $-P_{\mathrm{c}, \mathrm{vo}}$ fractional difference in isolated dog lung ranges $20-30 \%[6,9]$. When the inflection point technique is used, the $P_{\mathrm{c}, \text { ao }}-P_{\mathrm{c}, \mathrm{vo}}$ fractional difference in isolated lung is approximately $15 \%[8,11]$. Unexpectedly, the comparison of $P$ c,ao to $P$ c,vo and to $P$ c,do has yielded different results in intact animals. Using the zero-time extrapolation of the slow segment, $P_{\mathrm{c}}$,ao was at the same level as $P$ c,do in two recent studies in intact dog lung [1, 2]. Such discrepancy between the data of intact animal and isolated lung experiments could arise from the difficulties in obtaining a reliable measurement of $P_{\mathrm{c}, \text { do }}$ in intact animal. The measurement of $P \mathrm{c}$,do requires arterial and venous occlusions which are difficult to perform simultaneously in intact lung [13], either manually [1], or by an external clamp and an intravascular balloon $[2,13]$. However, the discrepancy between isolated lung and intact lung data

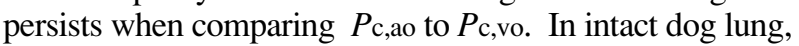
Holloway et al. [3] compared $P_{\mathrm{c}, \text { ao }}$ to $P_{\mathrm{c}, \mathrm{vo}}$ using the inflection point technique of analysis. In 45 of 49 data sets, $P$ c,ao was actually below the corresponding $P$ c,vo.

The concurrent results of the above studies cast doubt on the relevance of $P \mathrm{c}$,ao data measured in isolated lung, to intact lung. Before accepting such conclusions, we decided to compare again $P$ c,ao to $P$ c,vo in intact dog lung.
We first took advantage of this comparison to study the characteristics of the venous occlusion profiles in intact animal. We then confirmed that the $P$ c,ao $-P$ c,vo pressure gradient was approximately $10 \%$ in intact dog lung, supporting $P$ c,ao as a valid estimate of $P$ c in normal lung.

Estimations of capillary pressure from the venous and arterial postocclusion pressure curves in intact animals

The venous postocclusion pressure profile which is observed in the intact animal ([3], and this study), with a rapidly ascending phase followed by a slow exponential rise plateauing at the level of pulmonary arterial pressure, is similar to the profile observed in isolated lung using constant pressure perfusion mode [9, 14], because only one out of several pulmonary veins is occluded. It differs from the venous occlusion pressure-time profile with a rapidly ascending phase followed by a slow quasilinear rise in pressure [15], which is observed in isolated lung using constant flow perfusion mode, because all the pulmonary veins are occluded. The arterial postocclusion pressure profiles observed in the intact animal are similar to those observed in isolated lung, whether perfused at constant flow [6-8] or at constant pressure [9, 14].

We observed that the same data points were better fitted by a biexponential function than by a single exponential function in 36 out of 39 venous occlusion pressure profiles. The same was true for 34 out of 37 postocclusion arterial pressure profiles. The later observation agrees with those of DAwson et al. [1] and YAMADA et al. [16]. The fit of the arterial and venous occlusion pressure-time profiles by the sum of two exponentials, rather then by an instantaneous drop followed by a single exponential, suggests that compliant rather than resistive components predominate near the arterial and venous occlusion sites [17]. This suggests that the techniques of analysis of these profiles should be based on a model of the pulmonary circulation where the vascular compliance is presumably partitioned into arterial, middle, and venous compartments separated by an arterial and a venous resistance. We did not use the data of the initial components or the pressure profiles characterized by a short time constant for the estimation of capillary pressure, because potential deformations may affect this component $[2,18,19]$. As the inflection point cannot be formalized mathematically on a biexponential curve [17], we used the zero-time extrapolation of the slow segment to estimate $P$ c,ao and $P$ c,vo. This choice implies that $P$ c,ao would overestimate $P_{\mathrm{c}}$ and that $P_{\mathrm{c}, \text { vo }}$ would underestimate $P_{\mathrm{c}}$, if the arterial and venous compartments represent a substantial percentage of the middle compartment compliance [17].

\section{Longitudinal pulmonary pressure distributions obtained} from venous and arterial occlusions

Pulmonary arterial and venous pressures. Several factors may affect the measurement of arterial and venous pressure in our experiments. Firstly, the data acquisition of the arterial and venous postocclusion pressure profiles was 
performed separately in time and in location. Secondly, the measurements of venous and of arterial pressure give different results, whether they are measured by a catheter with a deflated balloon $(P \mathrm{a}$ and $P \mathrm{v})$ or using the late stable segment of the postocclusion profile $\left(P_{\mathrm{v}}\right.$,ao and $P$ a,vo $)$.

In the pooled data, $P_{\mathrm{v}}$ and $P_{\mathrm{v}, \text { ao }}$ were larger than $P_{\mathrm{LA}}$. The pressure gradient between $P_{\mathrm{V}}$ and $P_{\mathrm{LA}}$ may be explained by a partial obstruction of the lumen of the pulmonary vein by the venous catheter. Such a pressure gradient is related to the relative diameters of the catheter and of the pulmonary vein [20]. The pressure gradient between $P_{\mathrm{v}}$,ao and $P_{\text {LA }}$ may be explained by the pressure present downstream to the arterial occlusion. $P_{\mathrm{v}, \text { ao }}$ reflects the pressure at the junction between the pulmonary veins, which is situated at a lower level than the tip of the left atrial catheter.

A pressure gradient between $P$ a,vo and $P$ a may be observed as the balloon of the venous catheter, when inflated, increases the total vascular resistance. The $P$ a,vo$P$ a pressure gradient should be minimal when the tip of the venous catheter is in the nondependent lung, because the blood flow is preferentially distributed towards the dependent lung in the lateral position [21]. Consequently, the $P$ a,vo- $P$ a pressure gradient should enlarge when the venous catheter is in the dependent lung.

Considering the complexity of these various pressure gradients, $P$ a was chosen in the present study as the reference pressure for the pulmonary arterial pressure of the whole lung, and $P$ la as the reference pressure for the pulmonary venous pressure of the whole lung.

Capillary pressure estimates from arterial and venous occlusions. The levels of the $P_{\mathrm{c}}$ estimates using arterial and venous occlusion are related to the levels of $P$ a and $P$ v. This is exemplified in the group where the venous catheter was inserted in the dependent lung. We suggest that $P$ c,vo was above $P$ c,ao in this group because $P$ a,vo was above $P$ a (table 1). For a meaningful comparison of $P_{\mathrm{c}}$,ao to $P \mathrm{c}$,vo, the levels of $P$ a,vo and of $P_{\mathrm{v}, \text { ao }}$ or $P_{\mathrm{v}}$ can be normalized, respectively, to the levels of $P$ a and $P$ LA. Another possibility is to reference the $P_{\mathrm{c}}$ estimates from an arterial or a venous postocclusion profile to the arteriovenous pressure gradient measured on the same profile.

The levels of $P \mathrm{c}$,ao and $P \mathrm{c}$,vo are also related to the $P$ a$P \mathrm{c}$,ao and $P_{\mathrm{c}, \mathrm{vo}}-P_{\mathrm{v}}$ gradients, respectively. An increase in alveolar pressure will increase the gradient between $P$ c,ao and $P$ c,vo. It will, thus, decrease the $P$ a $-P$ c,ao and $P \mathrm{c}, \mathrm{vo}-P \mathrm{v}$ gradients by increasing $P \mathrm{c}$,ao and decreasing $P$ c,vo $[8,9]$. This effect was prevented by estimating $P$ c,ao in zone 3 condition by an arterial catheter inserted in the dependent lung. It was assumed that $P_{\mathrm{c}, \mathrm{vo}}$ was also measured in zone 3 condition even in the nondependent lung, as $P_{\mathrm{c}, \mathrm{vo}}$ is estimated from the final part of the venous occlusion curve and, hence, at high pressure. This assumption was tested by comparing the $P_{\mathrm{c}, \mathrm{vo}}-P_{\mathrm{v}}$ gradient in the nondependent lung and in the dependent lung. Although the difference was not significantly different between the two groups, the $P_{\mathrm{c}, \mathrm{vo}-} P_{\mathrm{v}}$ gradient was lower in the group where the venous catheter was inserted in the nondependent lung. This difference in $P_{\mathrm{c}, \mathrm{vo}}-P_{\mathrm{v}}$ gradient may also be explained by the difference in the blood flow perfusing the lung territory where the arterial or venous occlusion is performed. HAKIM and co-workers $[8,9]$ observed that the fractional $P_{\mathrm{c}, \mathrm{vo}}-P_{\mathrm{v}}$ gradient increased with blood flow in the isolated dog lung. As stated above, blood flow is preferentially distributed towards the dependent lung in the lateral position [21]. This could explain the higher level in $P_{\mathrm{c}, \mathrm{vo}}-P_{\mathrm{v}}$ gradient that was observed in the group where the venous catheter was inserted in the dependent lung, in the present study.

In the present study, it was considered that $P_{\mathrm{c}, \text { ao }}$ like $P$ c,vo cannot be compared directly because their values rely on: 1) the method of measurement of the venous and arterial pressures, depending on whether an arterial or a venous occlusion is performed; and 2) the conditions of perfusion of the lung territory where the arterial or the venous occlusion is performed. It was decided to reference the $P \mathrm{a}-P \mathrm{c}$,ao pressure gradient to the $P_{\mathrm{a}}-P_{\mathrm{v}}$,ao pressure gradient and to express it as a fractional arterial pressure gradient. Likewise, the $P_{\mathrm{c}, \mathrm{vo}-} P_{\mathrm{v}}$ pressure gradient was referenced to the $P$ a,vo- $P$ v pressure gradient and it was expressed as a fractional venous pressure gradient.

Mean capillary pressure. The fractional arterial and venous pressure gradients are separated by a fractional middle pressure gradient. A mean capillary pressure $(\bar{P} \mathrm{c})$ was calculated, half-way through the middle pressure gradient, referenced to the $P$ a- $P$ LA pressure gradient. $\bar{P}_{\mathrm{c}}$ was considered the best estimate of $P_{\mathrm{c}}$ that could be obtained in this study in intact lung. $\bar{P} \mathrm{c}$ made it possible to partition the $P$ a- $P$ LA pressure gradient into a precapillary and a postcapillary pressure gradient for 42 and $58 \%$, respectively. This partition is analogous to the $36-64 \%$ partition observed by HAKIM and co-workers [2], and to the 35-65\% partition observed by Dawson et al. [1]. In the present study, an increase was observed in the precapillary fraction of the arteriovenous pressure gradient following a serotonin infusion, confirming the data of previous studies $[1,2]$. It is, thus, reasonable to assume that $\overline{P_{\mathrm{c}}}$ is an alternative to $P_{\mathrm{do}}$ for the estimation of $P_{\mathrm{c}}$ in the intact dog lung.

\section{Middle pressure gradient}

Because the data of the initial component of the pressure profiles characterized by a short time constant could not be used for the estimation of capillary pressure, the value of $10 \pm 6 \%$ that was observed in the present study is considered an upper limit for the middle fraction of the $P$ a- $P$ v difference [17].

Comparison with the study of HoLlowAY et al. [3]. In the present study as in the study of Holloway et al. [3], the middle pressure gradient was estimated from the $P$ c,ao-

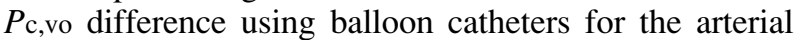
and venous occlusion in a similar intact lung preparation in dog. The fractional middle pressure gradient was $10 \pm 6 \%$ in the present study, as compared to a negative value in the study of Holloway et al. [3]. In addition to the different modes of normalization for the differences 
in the levels of the arterial and venous catheters [3], we suggest that the main difference between the two studies rests on the technique of analysis of the occlusion curves. The zero-time extrapolation of the slow segment was used to estimate $P$ c,ao and $P$ c,vo in the present study, whilst Holloway et al. [3] used the inflection point technique. These two techniques have been compared in the intact dog by HАKIM and co-workers [2]. They observed that $P_{\mathrm{c} \text {,ao calculated with the zero-time extrapola- }}$ tion of the slow segment technique correlated well with the estimation of $P \mathrm{c}$ by double occlusion $(P \mathrm{c}, \mathrm{do})$, whilst $P$ c,ao calculated with the inflection point technique underestimated $P$ c,do.

Comparison of the middle pressure gradient in the intact and isolated lung preparations. The difference between $P_{\mathrm{c}, \text { ao }}$ and $\overline{P_{\mathrm{c}}}$ in the present study is small. This is in agreement with the small negative difference between $P$ c,ao and $P$ c,vo in the study of Holloway et al. [3]. This is also in agreement with the small positive differences observed between $P_{\mathrm{c}}$,ao (as measured by the zero-time extrapolation of the slow segment) and $P$ c,do in the studies of HAKIM and co-workers [2] and DAwsON et al. [1] in the intact dog lung. This is at variance with the large middle pressure gradient observed with the later technique of analysis in isolated lung preparations [6, 9]. It may be argued that the comparison of $P_{\mathrm{c}, \text { vo values between }}$ isolated lung and intact lung is hindered by the shape of the venous postocclusion pressure profiles in the intact animal. However, this shape is not specific to the in vivo situation. It rather reflects the condition of perfusion at constant pressure. In isolated lung, using the zerotime extrapolation technique, the fractional middle pressure gradient was observed to be similar, whether the preparation was perfused with constant flow [6] or at constant pressure [9]. A similar observation was made by RIPPE et al. [14] with the inflection point technique, whether the isolated lung preparation was perfused with constant flow or at constant pressure.

Other factors may participate towards a low middle pressure gradient in the intact lung preparations. One factor is the sluggishness of the occlusion process when it is performed using an intravascular balloon [2, 22] instead of using an external clamp [16]. This may delay the time of complete occlusion and shorten the backextrapolation of the slow exponential segment, resulting in a lower $P_{\mathrm{c} \text {,ao }}$ and a higher $P_{\mathrm{c}, \mathrm{vo}}$. However, this explanation is not supported by the data of DAwson et al. [1], where $P_{\mathrm{c}, \text { ao }}$ and $P$ c,do were similar, although the occlusions were performed by pulling ligatures around the lobar artery and vein. Another factor may be the vasomotor tone present in the intact lung as compared to the isolated lung. LinEHAN [23] et al. observed a fractional middle pressure gradient of $46 \%$ when completely isolated lung lobes were used. In their next study [10], they observed a fractional middle pressure gradient of $26 \%$ when the lobes were still connected to the dog. LiNEHAN et al. [10] suggested that the intact lobes could be reached by endogenous vasomotor stimuli, explaining an increase in the arterial and venous resistances and a decrease in fractional middle pressure gradient. Such an explanation is supported by the modifications in the segmental pressure distribution brought about by the infusion of nitroprusside, a vasodilatating substance, in the present study. It was associated with a decrease in the fractional arterial and venous pressure gradients, leading to an increase in the fractional middle pressure drop from $8 \pm 23 \%$ to $19 \pm 25 \%$. Another explanation for the low middle pressure gradient in the intact lung preparations is the pulsatile blood flow in vivo as compared to the steady blood flow through an isolated lung. RAJ et al. [24], measuring pressures in subpleural 20-50 $\mu \mathrm{m}$ diameter arterioles and venules in the adult rabbit by use of micropipettes, observed that the fractional microvascular pressure gradient was $28 \%$ in the anaesthetized animal, instead of $55 \%$ in the isolated lung. Changes in a similar direction were observed when isolated lungs were perfused with pulsatile, instead of steady, blood flows.

\section{Conclusion}

In conclusion, the measured effects of a stimulus, i.e. a mediator or a pharmacological substance, on the pulmonary circulation cannot be extrapolated from an isolated lung preparation to an intact animal, because indirect effects of the stimulus through its actions on the systemic circulation are added to its direct effects on the pulmonary circulation. The absence of pulsatility and the modifications involved by the process of isolation of the lung, may be another source of differences between the isolated lung and the intact lung. The data of the present study are in keeping with those of previous studies in intact lung [1-3]. They support the use of $P_{\mathrm{c}}$,ao as an estimate of $P_{\mathrm{c}}$ in intact lung. However, this conclusion is drawn from studies on normal lung in one species. It should not be extended to situations where the lung is injured and/or submitted to high alveolar pressures, two situations where the measurement of $P_{\mathrm{c}}$ is the most useful in critical care patients. Further work is needed before concluding that $P \mathrm{c}$,ao remains a good estimate of $P_{\mathrm{c}}$ in such situations.

Acknowledgments: The authors thank M. Delaire for her valuable technical assistance.

\section{References}

1. Dawson CA, Bronikowski TA, Linehan JH, Haworth ST, Rickaby DA. On the estimation of pulmonary capillary pressure from arterial occlusion. Am Rev Respir Dis 1989; 140: 1228-1236.

2. Hakim TS, Maarek J-M, Chang KH. Estimation of pulmonary capillary pressure in intact dog lungs using the arterial occlusion technique. Am Rev Respir Dis 1989; 140: 217-224.

3. Holloway H, Perry M, Downey J, Parker J, Taylor A. Estimation of effective pulmonary capillary pressure in intact lungs. J Appl Physiol: Respirat Environ Exercise Physiol 1983; 54: 846-851.

4. Collee GC, Lynch K, Hill RD, Zapol WM. Bedside measurement of pulmonary capillary pressure in patients 
with acute respiratory failure. Anesthesiol 1987; 66: 614-620.

5. Cope DK, Allison RC, Parmentier JL, Miller JN, Taylor AE. Measurement of effective pulmonary capillary pressure using the pressure profile after pulmonary artery occlusion. Crit Care Med 1986; 14: 16-22.

6. Rock P, Patterson GA, Permutt S, Sylvester JT. Nature and distribution of vascular resistance in hypoxic pig lungs. J Appl Physiol 1985; 59: 1891-1901.

7. Hakim TS. Identification of constriction in large versus small vessels using the arterial-venous and the doubleocclusion techniques in isolated canine lungs. Respiration 1988; 54: 61-69.

8. Hakim TS, Michel RP, Chang KH. Partitioning of pulmonary vascular resistance in dogs by arterial and venous occlusion. J Appl Physiol: Respirat Environ Exercise Physiol 1982; 52: 710-715.

9. Hakim TS. Criteria for analysis of arterial and venous occlusion. J Appl Physiol 1991; 70: 665-675.

10. Linehan JH, Dawson CA. A three-compartment model of the pulmonary vasculature: effects of vasoconstriction. J Appl Physiol: Respirat Environ Exercise Physiol 1983; 55: 923-928.

11. Hakim TS, Michel RP, Minami H, Chang KH. Site of pulmonary hypoxic vasoconstriction studied with arterial and venous occlusion. J Appl Physiol: Respirat Environ Exercise Physiol 1983; 54: 1298-1302.

12. Grimbert FA, Martin DJ, Parker JC, Taylor AE. Pulmonary blood flow vs microvascular pressure effects on lung lymph flow in dogs. Am J Physiol (Heart Circ Physiol) 1988; 255: H1149-H1155.

13. Hakim TS, Maarek J-M, Chang KH. Estimation of pulmonary capillary pressure in intact dog lungs using the arterial occlusion technique. Letter: Reply. Am Rev Respir Dis 1990; 141: 1602-1603.

14. Rippe B, Parker JC, Townsley M, Mortillaro NA, Taylor
AE. Segmental vascular resistances and compliances in the dog lung. J Appl Physiol 1987; 62: 1206-1215.

15. Hakim TS, Dawson CA, Linehan JH. Hemodynamic responses of dog lung lobe to lobar venous occlusion. $J$ Appl Physiol: Respirat Environ Exercise Physiol 1979; 47: 145-152.

16. Yamada Y, Suzukawa M, Chinzei M, et al. Phasic capillary pressure determined by arterial occlusion in intact dog lung lobes. J Appl Physiol 1990; 67: 2205-2211.

17. Baconnier P, Eberhard A, Grimbert FA. A theoretical analysis of occlusion techniques for measuring pulmonary capillary pressure. J Appl Physiol 1992: 73: 1351-1359.

18. Audi SH, Dawson CA, Rickaby DA, Linehan JH. Localization of the sites of pulmonary vasomotion by use of arterial and venous occlusion. J Appl Physiol 1991; 70: 2126-2136.

19. Linehan JH, De Mora F, Bronikowski TA, Dawson CA. Hemodynamic modelling of vascular occlusion experiments in cat lung. Adv Bioeng 1988; 8: 139-142.

20. Nicolaysen G, Shepard J, Tanita T, Onizuka M, Hall C, Staub NC. Effect of catheter size on pressures recorded in small pulmonary veins in dog lung. J Appl Physiol 1991; 71: 1296-1301.

21. Wulff KE, Aulin I. The regional lung function in the lateral decubitus position during anesthesia and operation. Acta Anaesthesiol Scand 1972; 16: 195-205.

22. Gilbert E, Hakim TS. Derivation of pulmonary capillary pressure from arterial occlusion in intact conditions. Crit Care Med 1994; 22: 986-993.

23. Linehan JH, Dawson CA, Rickaby DA. Distribution of vascular resistance and compliance in a dog lung lobe. J Appl Physiol: Respirat Environ Exercise Physiol 1982; 53: 156-168.

24. Raj JU, Kaapa P, Anderson J. Effect of pulsatile flow on microvascular resistance in adult rabbit lungs. J Appl Physiol 1992; 72: 73-81. 